\title{
A Power-Efficient Multichannel Low-Pass Filter Based on the Cascaded Multiple Accumulate Finite Impulse Response (CMFIR) Structure for Digital Image Processing
}

\author{
Vivek Jain ${ }^{1}$ - Prasun Chakrabarti ${ }^{1}$ - Massimo Mitolo ${ }^{2}$. \\ Zbigniew Leonowicz ${ }^{3}$ (D) Michal Jasinski ${ }^{3}$ - Alexander Vinogradov ${ }^{4}$. \\ Vadim Bolshev ${ }^{4}$ iD
}

Received: 16 November 2020 / Revised: 30 December 2021 / Accepted: 5 January 2022 /

Published online: 10 February 2022

(c) The Author(s) 2022

\begin{abstract}
The author offers a power-efficient multichannel low-pass filter for digital image processing based on the cascade multiple accumulate finite impulse response (CMFIR) structure in this study. The CMFIR filter was created using the outputs of a linear time-invariant system (LTI), which was built using a cascaded integrator comb (CIC) and a MAC low-pass filter. The sample rate convertor based on CIC filters effectively conducts decimation or interpolation. The sample rate convertor with the CIC filter can only accommodate narrowband transmissions and so cannot be utilized for wideband signals. The MAC architecture-based sample rate convertor is a good solution for high-bandwidth signals, but it uses more resources like registers and flip-flops, which increases power consumption. Here, the CMFIR low-pass filter acts as an interpolator, introducing a sample to boost the image's resolution. CMFIR is a useful tool for addressing the issue of aliasing during sampling. In addition, the genetic algorithm was used to increase the filter's resource utilization and power consumption efficiency.
\end{abstract}

Keywords Linear time-invariant system - Cascaded multiple accumulate finite impulse response $\cdot$ Cascaded integrator comb $\cdot$ Multiple accumulate unit · Intensity

\section{Introduction}

Digital image processing applications are indicated in many areas of the present world $[8,24]$ such as medicine (e.g., microscopes [21], digital mammography [7], X-ray computed tomography [28]), automotive applications (e.g., license plate recognition[4],

Michal Jasinski

michal.jasinski@pwr.edu.pl

Extended author information available on the last page of the article 
dimensional verification of crankshafts [15], detection of objects [29]), geo engineering (maps classification [2], detection of Earth's surface features changes[34]), industrial applications (package inspection [17], sorting [6], quality inspection[36]).

The filtering technique is a part of the normal image enhancement process. It helps in solving problems of the image display [10] and, additionally, enables the improvement of image quality. The problems that always happened in images are illumination, noise, and under-light images [20]. Hence, one of the challenges is to remove noise from images $[16,32]$. Therefore, there is a need to develop a sample converter that works as a low-pass filter to remove the noise from images at low power consumption [13, 26].

A low-pass filter is used to avoid aliasing in the linear time-invariant (LTI) system $[22,38]$. In the past, the Cascaded Integrator Comb finite impulse response (CIC FIR) filter was employed as a low-pass filter. However, the sample rate converter using the CIC filter has limitations in supporting only narrowband signals and thus cannot be used for large bandwidth signals [11, 18, 19]. A multiply-accumulator (MAC) architecture-based sample rate converter is an efficient solution for large bandwidth signals, but it requires additional resources such as registers and flip-flops which lead to an increase in power consumption [14, 25, 31].

To optimize the sample rate converter in terms of acceptable power consumption, we have developed a model named Cascaded Multiple Accumulate Finite-Impulse Response (CMFIR) filter-based sample rate converters [12]. The CMFIR filter is the combination of CIC FIR and MAC FIR filters incorporating promising features of both filters [35].

To reduce the power consumption of the sample rate converter, we apply the multi-objective genetic algorithm on coefficients of the CMFIR filter. The power consumption of the multichannel sample rate converter is reduced by minimizing the hamming distance between the successive coefficients of the CMFIR filter. Eventually, we have developed a multichannel up sample rate converter, where time-division multiplexing is used to increase the number of channels. The number of channels is selected based on the intensity level of the light via artificial intelligence [35].

Then the comparison between CMFIR architecture-based up converter with genetic algorithm application and CIC Filter, MAC Filter, and CMFIR architecture-based up converter without genetic algorithm was realized in point of static power consumption efficiency, dynamic power consumption efficiency, total power consumption efficiency, register utilization efficiency, LUT utilization efficiency, LUT-flip flop pairs utilization efficiency. Additionally, the comparison with results of the literature position was realized concerning total power and device utilization like LUT, flip flop, and slice LUT-flip flop pairs.

The article is organized as follows: Sect. 2 presents the background for the proposed solution in the article. Section 3 shows the efficiency of the proposed CMFIR structure. Section 4 is a discussion of the proposed structure to other literature propositions. Section 5 concludes and indicates possible appliances. 


\section{Methods}

\subsection{Mathematical Modeling of the FIR Filter}

1. As recorded from the synthesis report following simulation of the proposed model, the time required to produce the output was approximately equal to $3.259 \mathrm{~ns}$, including $2.923 \mathrm{~ns}$ was the logical delay, and $0.336 \mathrm{~ns}$ was for the routing delay. We set the number of iterations $(\mathrm{N})$ in the genetic algorithm as 10 .

2. Ripple in the passband was 0.01 , the corresponding value of the passband angular frequency $\mathrm{w}_{\mathrm{p}}$ was $0.18 \pi$.

3. Ripple in the stopband was 0.01 , the corresponding value of stopband angular frequency $\mathrm{w}_{\mathrm{s}}$ was $0.22 \pi 7$ [23].

The fitness function for the genetic algorithm is given by:

$$
U(x)=\frac{1}{f(x)}+\mu(\mathrm{SNZ})
$$

$U(x)=$ Fitness Function. $f(x)=$ Initially generated filter coefficient using Kaiser window techniques. SNZ $=$ Sum of non-zero. $M=$ Transition Bandwidth Constant.

Transition bandwidth is given by:

$$
w_{s}-w_{p}=2 * \pi\left(f_{s}-f_{p}\right)=2 * \pi * \delta f=2 * \pi *\left(\frac{\mu}{N}\right),
$$

where $N=$ Number of the iteration, $f_{s}=$ Stop band frequency, $f_{p}=$ Pass band frequency, $w_{s}=$ Stop band angular frequency, $w_{p}=$ Pass band angular frequency.

The transition bandwidth of design is: $0.04 * \pi$

$$
0.04 * \pi=2 * \pi *\left(\frac{\mu}{10}\right)
$$

By solving Eq. 3, we get the value of $\mu$ to be 0.2 [23].

\subsection{Genetic Algorithm}

A genetic algorithm is applied to the coefficient of the filter to reduce the hamming distance. The basic steps of genetic algorithm implementation are described in Fig. 1 [27].

1. Evaluate the fitness function: The fitness function is defined over the genetic representation and measures the quality of the generated coefficient. The fitness function here is used to generate the filter coefficients to meet the requirement. In the current research problem, the fitness function for the genetic algorithm is given by:

$$
U(x)=\frac{1}{f(x)}+\mu(\mathrm{SNZ})
$$




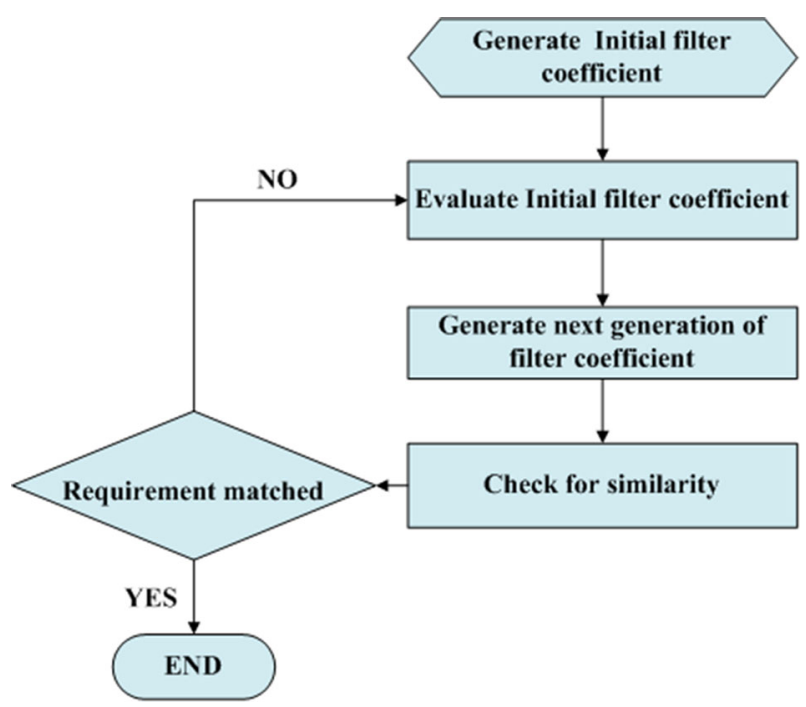

Fig. 1 Genetic algorithm flow chart

2. Selection: During every consecutive generation of the filter coefficients, a proportion of the existing coefficients is selected to generate the class of new coefficients.

3. Crossover: By applying the mathematical operation on the existing generation of coefficients, the next generation of coefficients is achieved.

4. Mutation: With the help of mutation, we ensure that the new coefficient is not similar to the parent coefficient [27].

\subsection{Analysis in Light of Artificial Intelligence}

The intensity of fog can be predicted based on various learning rules [1, 30, 33]. Initially, a study of the fog intensities over a certain period of time has to be carried out. Afterward, the regular, irregular, seasonal and cyclic variations of data at the location of interest need to be carefully analyzed for generating a particular mathematical model. The curve fitting can also be applied in this perspective, and a polynomial of the degree of $\mathrm{n}$ will be generated. Exponential growth models can also be sensed in order to find out a relation between the fog intensity level and the corresponding time instant. The mathematical representation is as follows:

$$
I_{F . t}=a e^{t}
$$

where $I_{F . t}=$ fog intensity level at t time, $a=$ amplitude of fog noise.

Let the timing interval of observation be $t_{1}, t_{2}, t_{3}, t_{4}$, and it is in equivalent nature.

$$
I_{F . t 1}=a e^{t 1}, I_{F . t 2}=a e^{t 2},
$$


In the case of mid-interval pattern analysis is given by:

$$
\begin{gathered}
I_{F \cdot \frac{t 1+t 2}{2}}=a e^{\frac{t 1+t 2}{2}}, \\
I_{F \cdot \frac{t 1+t 2}{2}}=\left[a^{2} e^{t 1+t 2}\right]^{\frac{1}{2}}, \\
I_{F \cdot \frac{t 1+t 2}{2}}=\left[a e^{t 1} \cdot a e^{t 2}\right]^{\frac{1}{2}}, \\
I_{F \cdot \frac{t 1+t 2}{2}}=\left[I_{F, t 1} \cdot I_{F, t 2}\right]^{\frac{1}{2}},
\end{gathered}
$$

\subsection{Power Utilization}

When FIR is implemented on FPGA, the design on FPGA is developed by the interconnection of various gate arrays. The gates are implemented by CMOS transistor. By reducing the hamming distance of successive coefficients of CMFIR filter, it reduces the switching of CMOS transistor for the transition from 0 to 1 or 1 to 0 without affecting the frequency response of a multichannel fractional sample rate convertor. Thus, the power utilization of a multichannel fractional sample rate converter is reduced. The total power utilization is given by [9]:

$$
\begin{gathered}
P_{T}=P_{\text {static }}+P_{\text {dynamic }}, \\
P_{\text {dynamic }}=P_{t}+P_{c}, \\
P_{t}=C_{d p} * V_{s s}^{2} * f_{i} * B_{t}, \\
P_{c}=C_{l} * V_{s s}^{2} * f_{o} * B_{t},
\end{gathered}
$$

where $P_{T}=$ Total power used by CMOS transistor, $P_{\text {static }}=$ Static power, $P_{\text {dynamic }}$ $=$ Dynamic power, $P_{t}=$ Power consume in Transient Response of capacitance, $P_{c}=$ Power consume by Capacitive load, $C_{d p}=$ Dynamic power dissipation in capacitance, $B_{t}=$ Number of bits changes from 0 to 1 or 1 to 0 of consecutive CMFIR filter coefficient, $f_{i}=$ Input signal frequency, $f_{o}=$ Output signal frequency $[9,37]$.

\subsection{Objective}

- To design \& optimize a suitable CM FIR filter using CIC and MAC Unit for removing the remove the noise from the digital image.

- Increase power efficiency and resource utilization efficiency. 
Fig. 2 Workflow chart

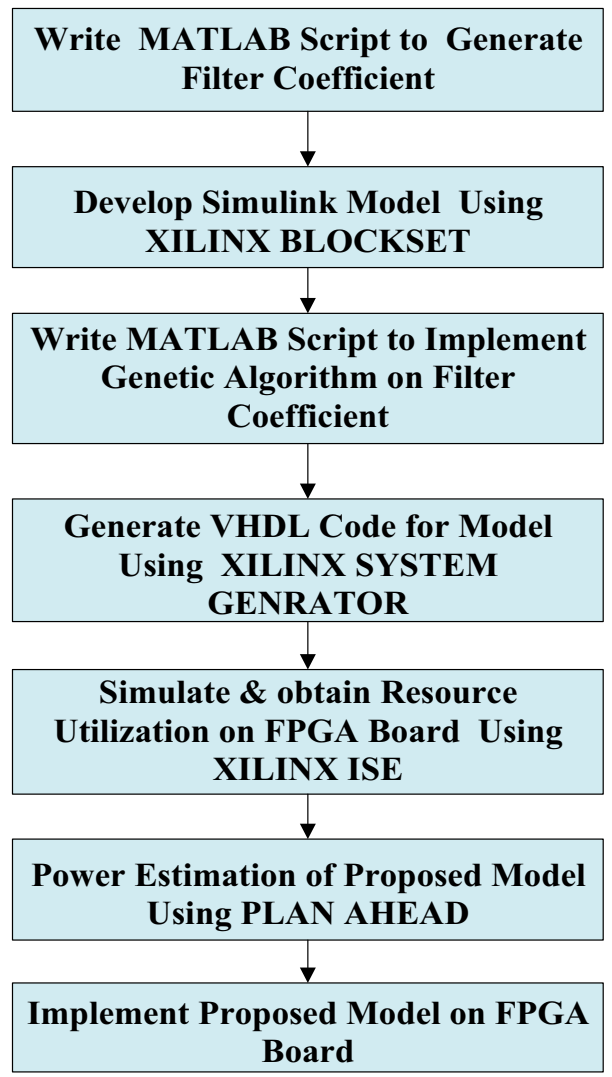

\subsection{Work Flow}

(Fig. 2).

\section{Result}

In this section, the comparison between the proposed CMFIR architecture-based up converter with genetic algorithm application and:

- CMFIR Filter without genetic algorithm application,

- CIC Filter,

- MAC Filter.

Firstly, the comparison between CMFIR Filter with and without genetic algorithm is realized in the basement of the hamming distance between coefficients. Results are indicated in Table 1. The results show that the total Hamming distance for CMFIR filter before application of GA (genetic algorithm) is equal to 77 and after it is equal to 50. Therefore, the application of GA (genetic algorithm) enables the reduction of the hamming distance by 27. 
Table 1 Hamming distance between the coefficients of CMFIR filter with and without genetic algorithm

Hamming distance between the coefficients of CMFIR filter

\begin{tabular}{|c|c|c|c|c|c|}
\hline \multicolumn{3}{|c|}{ Without genetic algorithm } & \multicolumn{3}{|c|}{ With genetic algorithm } \\
\hline $\begin{array}{l}\text { Value in } \\
\text { integer }\end{array}$ & Value in binary & $\begin{array}{l}\text { Hamming } \\
\text { distance }\end{array}$ & $\begin{array}{l}\text { Value in } \\
\text { integer }\end{array}$ & Value in binary & $\begin{array}{l}\text { Hamming } \\
\text { distance }\end{array}$ \\
\hline 0.05936 & 0.0000111100110010 & 0 & 0.04299 & 0.0000101100000001 & 0 \\
\hline 0.09885 & 0.0001100101001110 & 7 & 0.04569 & 0.0000101110110010 & 5 \\
\hline 0.11730 & 0.0001111000000111 & 6 & 0.09395 & 0.0001100000110010 & 4 \\
\hline 0.03713 & 0.0000100110000001 & 7 & 0.04947 & 0.0000110010101010 & 5 \\
\hline 0.44611 & 0.0111001000110100 & 11 & 0.31859 & 0.0101000110001110 & 7 \\
\hline 0.37935 & 0.0110000100011111 & 7 & 0.45713 & 0.0111010100000110 & 4 \\
\hline 0.44611 & 0.0111001000110100 & 7 & 0.31859 & 0.0101000110001110 & 4 \\
\hline 0.03713 & 0.0000100110000001 & 11 & 0.04947 & 0.0000110010101010 & 7 \\
\hline 0.11730 & 0.0001111000000111 & 7 & 0.09395 & 0.0001100000110010 & 5 \\
\hline 0.09885 & 0.0001100101001110 & 6 & 0.04569 & 0.0000101110110010 & 4 \\
\hline 0.05936 & 0.0000111100110010 & 8 & 0.04299 & 0.0000101100000001 & 5 \\
\hline
\end{tabular}

Then the comparison between CMFIR architecture-based up converter with genetic algorithm application and CIC Filter, MAC Filter, and CMFIR architecture-based up converter without genetic algorithm was realized in point of:

- Static power consumption efficiency, Dynamic power consumption efficiency, Total power consumption efficiency:

$$
\text { Power efficiency }=\left(\frac{P_{\text {old }}-P_{\text {new }}}{P_{\text {old }}}\right) \times 100
$$

- Where $P_{\text {old }}$ is the power consumed by the old or existing model

- Where $P_{\text {new }}$ is the power consumed by the new or proposed model

- Power efficiency is more means system is power consumption decreases.

- Register utilization efficiency, LUT Utilization efficiency, LUT-flip flop pairs utilization efficiency:

$$
\text { Resource utilization efficiency }=\left(\frac{R_{\text {old }}-R_{\text {new }}}{R_{\text {old }}}\right) \times 100
$$

- Where $R_{\text {old }}$ is resource utilization by the old or existing model.

- Where $R_{\text {new }}$ is resource utilization by the new or proposed model.

- Resource utilization efficiency is more means resource utilization decreases.

Figure 3 and Table 2 present the efficiency CMFIR architecture-based up converter with genetic algorithm application versus CIC Filter, MAC Filter, and CMFIR 


\section{STATIC POWER CONSUMPTION EFFICIENCY GRAPH}

- with respect to MAC Filter Architecture Based Up Converter (\%)

— with respect to CIC Filter Architecture Based Up Converter (\%)

— with respect to CMFIR Architecture Based Up Converter Without Genetic Algorithm (\%)

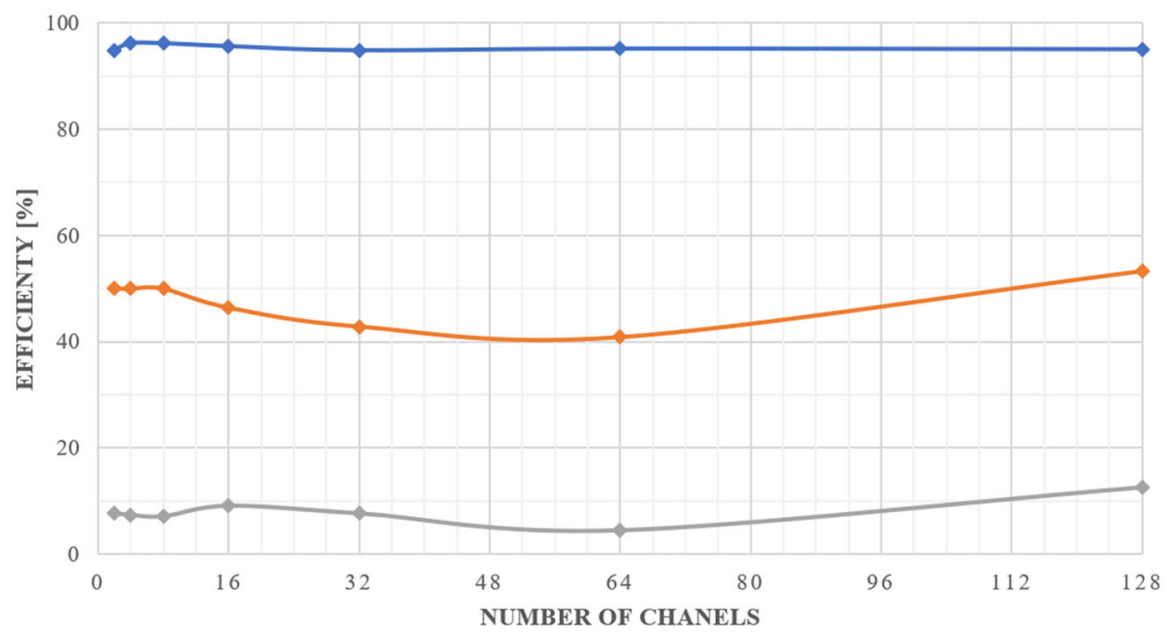

Fig. 3 Static power consumption efficiency graph with respect to other structures

Table 2 Static power efficiency of CMFIR architecture-based up converter with genetic algorithm with respect to other up converters

\begin{tabular}{lllllllll}
\hline Number of channel(s) & 1 & 2 & 4 & 8 & 16 & 32 & 64 & 128 \\
\hline $\begin{array}{l}\text { CMFIR architecture-based } \\
\text { up converter with genetic } \\
\text { algorithm efficiency with }\end{array}$ & 93.92 & 94.92 & 96.21 & 96.20 & 95.66 & 94.89 & 95.19 & 95.08 \\
$\begin{array}{l}\text { respect to MAC filter } \\
\text { architecture-based up } \\
\text { converter (\%) }\end{array}$ & & & & & & & & \\
$\begin{array}{l}\text { CMFIR architecture-based } \\
\text { up converter with genetic }\end{array}$ & 50.00 & 50.00 & 50.00 & 50.00 & 46.43 & 42.86 & 40.85 & 53.33 \\
$\begin{array}{l}\text { algorithm efficiency with } \\
\text { respect to CIC filter } \\
\text { architecture-based up } \\
\text { converter (\%) }\end{array}$ & & & & & & & & \\
$\begin{array}{l}\text { CMFIR architecture-based } \\
\text { up converter with genetic } \\
\text { algorithm efficiency with } \\
\text { respect to CMFIR } \\
\text { architecture-based up } \\
\text { converter without } \\
\text { genetic algorithm (\%) }\end{array}$ & 8.00 & 7.69 & 7.41 & 7.14 & 9.09 & 7.69 & 4.55 & 12.50 \\
\hline
\end{tabular}




\section{DYNAMIC POWER CONSUMPTION EFFICIENCY GRAPH}

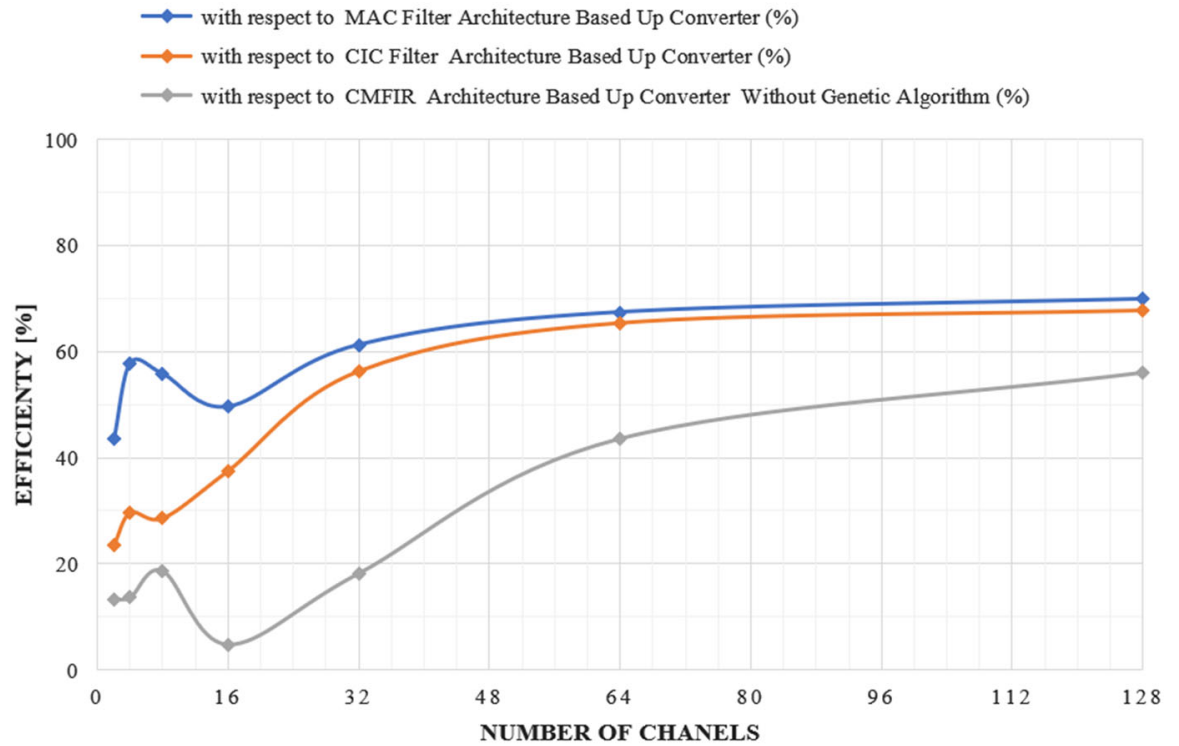

Fig. 4 Dynamic power consumption efficiency graph with respect to other structures

architecture-based up converter without genetic algorithm in point of static power consumption.

Figure 4 and Table 3 present the efficiency of CMFIR architecture-based up converter with genetic algorithm application versus CIC Filter, MAC Filter, and CMFIR architecture-based up converter without genetic algorithm in point of dynamic power consumption.

Figure 5 and Table 4 present the efficiency of CMFIR architecture-based up converter with genetic algorithm application versus CIC Filter, MAC Filter, and CMFIR architecture-based up converter without genetic algorithm in point of total power consumption.

Figure 6 and Table 5 present the efficiency of CMFIR architecture-based up converter with genetic algorithm application versus CIC Filter, MAC Filter, and CMFIR architecture-based up converter without genetic algorithm in point of for register utilization.

Figure 7 and Table 6 present the efficiency of CMFIR architecture-based up converter with genetic algorithm application versus CIC Filter, MAC Filter, and CMFIR architecture-based up converter without genetic algorithm in point of LUT utilization.

Figure 8 and Table 7 presents the efficiency of CMFIR architecture-based up converter with genetic algorithm application versus CIC Filter, MAC Filter, and CMFIR architecture-based up converter without genetic algorithm in point of LUT - flip flop pairs utilization. 
Table 3 Dynamic power efficiency of CMFIR architecture-based up converter with genetic algorithm with respect to other up converters

\begin{tabular}{lllllllll}
\hline Number of channel(s) & 1 & 2 & 4 & 8 & 16 & 32 & 64 & 128 \\
\hline $\begin{array}{l}\text { CMFIR architecture-based } \\
\text { up converter with genetic }\end{array}$ & 26.67 & 43.48 & 57.78 & 55.70 & 49.58 & 61.24 & 67.38 & 69.86 \\
$\begin{array}{l}\text { algorithm efficiency with } \\
\text { respect to MAC filter } \\
\text { architecture-based up } \\
\text { converter (\%) }\end{array}$ & & & & & & & & \\
$\begin{array}{l}\text { CMFIR architecture-based } \\
\text { up converter with genetic }\end{array}$ & 15.38 & 23.53 & 29.63 & 28.57 & 37.50 & 56.22 & 65.28 & 67.65 \\
$\begin{array}{l}\text { algorithm efficiency with } \\
\text { respect to CIC filter } \\
\text { architecture-based up } \\
\text { converter (\%) }\end{array}$ & & & & & & & & \\
$\begin{array}{l}\text { CMFIR architecture-based } \\
\text { up converter with genetic } \\
\text { algorithm efficiency with } \\
\text { respect to CMFIR } \\
\text { architecture-based up } \\
\text { converter without } \\
\text { genetic algorithm (\%) }\end{array}$ & 8.33 & 13.33 & 13.64 & 18.60 & 4.76 & 18.18 & 43.56 & 56.00 \\
\hline
\end{tabular}

\section{TOTAL POWER CONSUMPTION EFFICIENCY GRAPH}

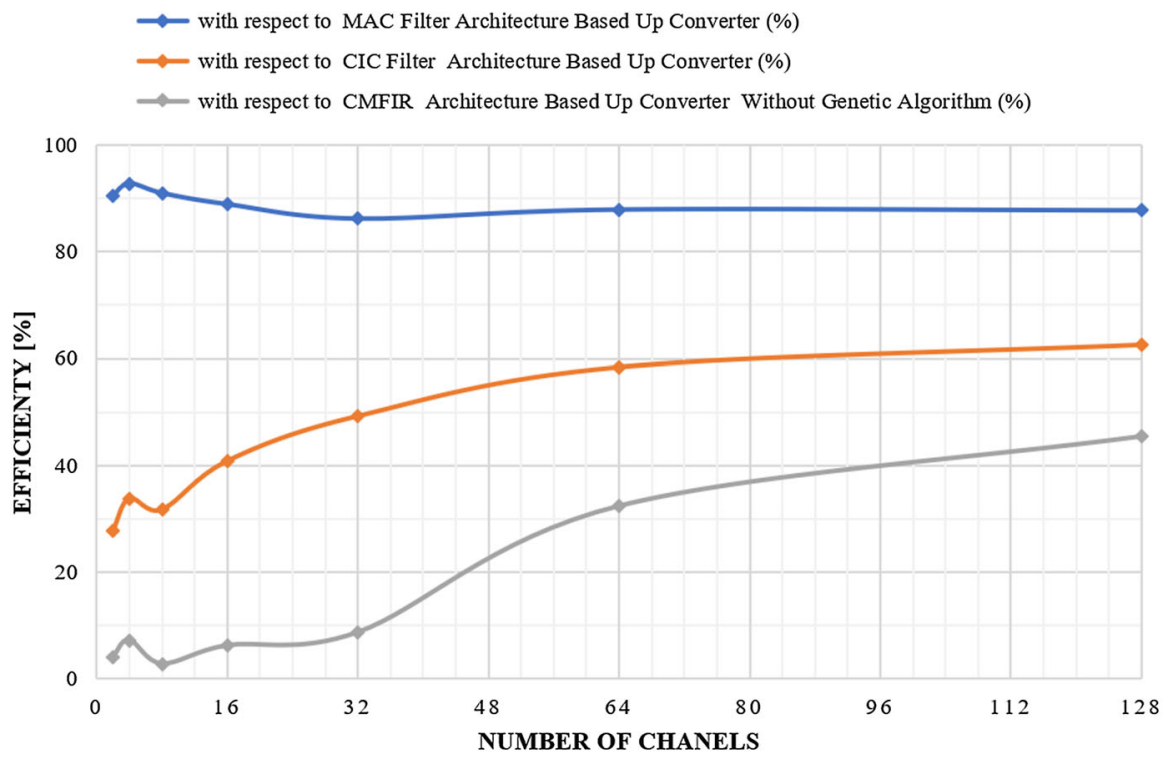

Fig. 5 Total power consumption efficiency graph with respect to other structures 
Table 4 Total power efficiency of CMFIR architecture-based up converter with genetic algorithm with respect to other up converters

\begin{tabular}{|c|c|c|c|c|c|c|c|c|}
\hline Number of channel(s) & 1 & 2 & 4 & 8 & 16 & 32 & 64 & 128 \\
\hline $\begin{array}{l}\text { CMFIR architecture-based } \\
\text { up converter with genetic } \\
\text { algorithm efficiency with } \\
\text { respect to MAC filter } \\
\text { architecture-based up } \\
\text { converter }(\%)\end{array}$ & 90.33 & 90.51 & 92.76 & 90.96 & 88.89 & 86.20 & 87.88 & 87.73 \\
\hline $\begin{array}{l}\text { CMFIR architecture-based } \\
\text { up converter with genetic } \\
\text { algorithm efficiency with } \\
\text { respect to CIC filter } \\
\text { architecture-based up } \\
\text { converter }(\%)\end{array}$ & 35.59 & 27.69 & 33.77 & 31.68 & 40.79 & 49.19 & 58.33 & 62.47 \\
\hline $\begin{array}{l}\text { CMFIR architecture-based } \\
\text { up converter with genetic } \\
\text { algorithm efficiency with } \\
\text { respect to CMFIR } \\
\text { architecture-based up } \\
\text { converter without } \\
\text { genetic algorithm }(\%)\end{array}$ & 19.15 & 4.08 & 7.27 & 2.82 & 6.25 & 8.70 & 32.37 & 45.42 \\
\hline
\end{tabular}

\section{REGISTER UTILIZATION EFFICIENCY GRAPH}

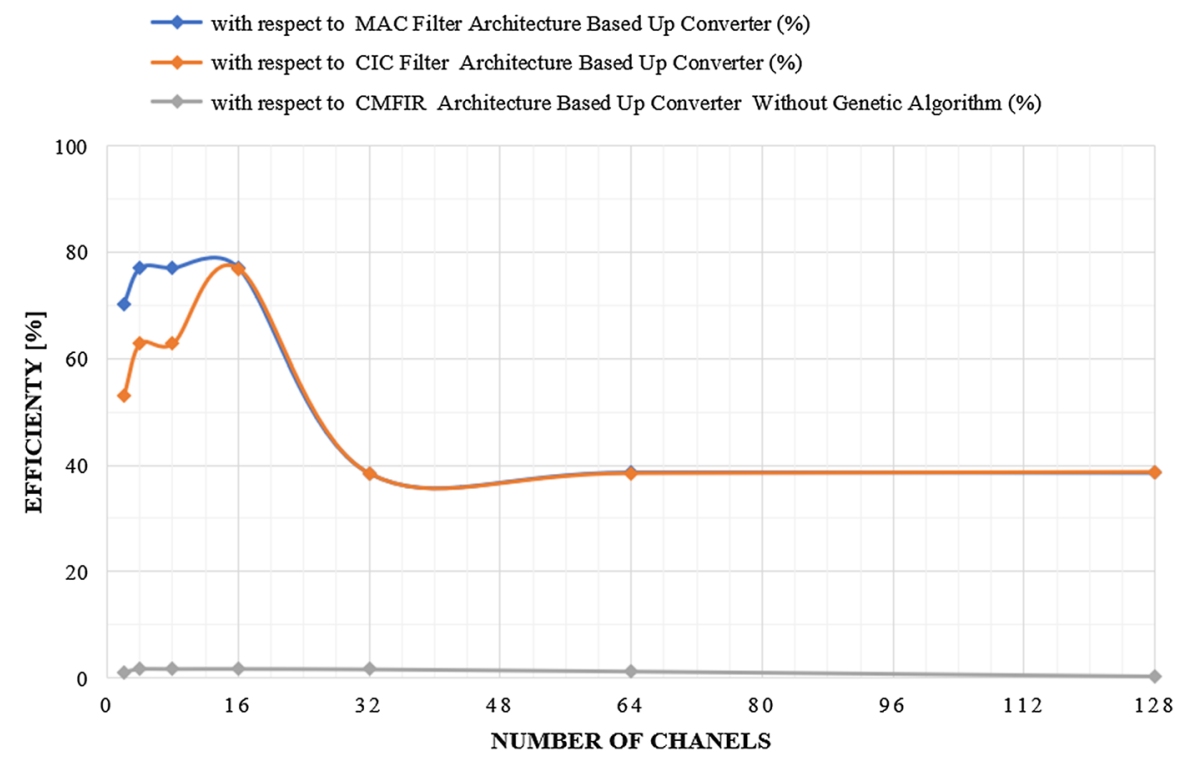

Fig. 6 Register utilization efficiency graph with respect to other structures 
Table 5 Efficiency table of register utilization of CMFIR architecture-based up converter with genetic algorithm with respect to other up converters

\begin{tabular}{|c|c|c|c|c|c|c|c|}
\hline Number of channel(s) & 2 & 4 & 8 & 16 & 32 & 64 & 128 \\
\hline $\begin{array}{l}\text { CMFIR architecture-based up } \\
\text { converter with genetic algorithm } \\
\text { efficiency with respect to MAC } \\
\text { filter architecture-based up } \\
\text { converter }(\%)\end{array}$ & 70.30 & 77.00 & 76.98 & 76.98 & 38.48 & 38.66 & 38.59 \\
\hline $\begin{array}{l}\text { CMFIR architecture-based up } \\
\text { converter with genetic algorithm } \\
\text { efficiency with respect to CIC } \\
\text { filter architecture-based up } \\
\text { converter }(\%)\end{array}$ & 53.06 & 62.92 & 62.81 & 76.93 & 38.49 & 38.55 & 38.77 \\
\hline $\begin{array}{l}\text { CMFIR architecture-based up } \\
\text { converter with genetic } \\
\text { algorithm efficiency with } \\
\text { respect to CMFIR } \\
\text { architecture-based up converter } \\
\text { without genetic algorithm (\%) }\end{array}$ & 1.14 & 1.71 & 1.73 & 1.74 & 1.65 & 1.24 & 0.28 \\
\hline
\end{tabular}

\section{LUT UTILIZATION EFFICIENCY GRAPH}

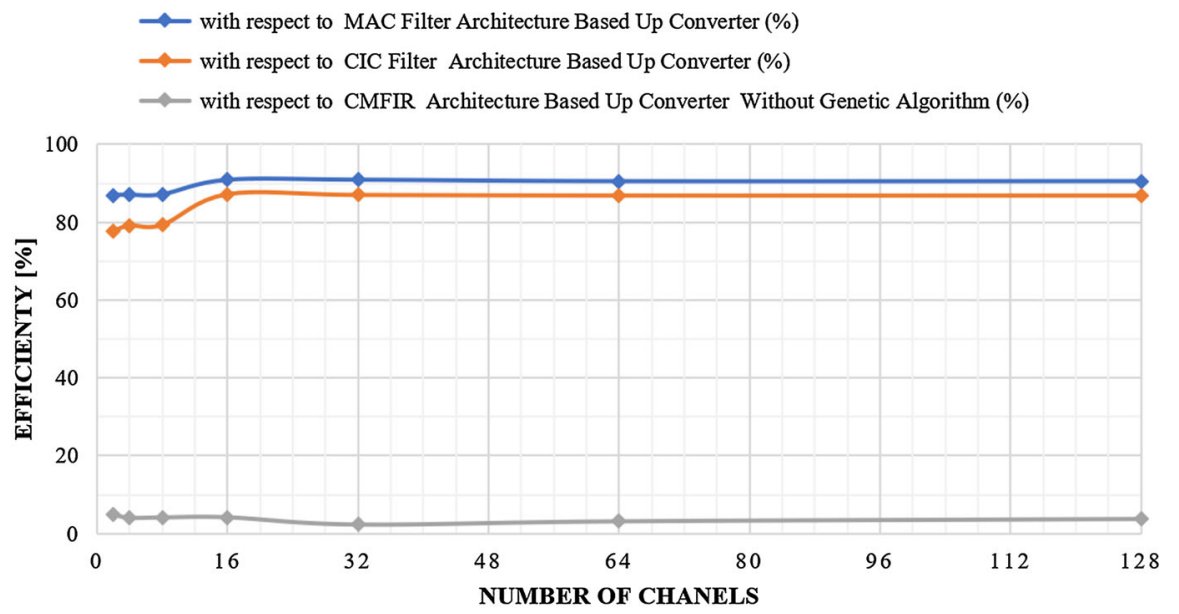

Fig. 7 LUT utilization efficiency graph with respect to other structures

\section{Discussion}

With an applied genetic algorithm model to the CMFIR approach, the overall hamming distance is reduced by 27 . The multichannel CMFIR-based converter efficiency has been also improved in terms of power \& resource utilization. More specifically, the following observations are made: 
Table 6 Efficiency table of LUT utilization of CMFIR architecture-based up converter with genetic algorithm with respect to other up converters

\begin{tabular}{|c|c|c|c|c|c|c|c|}
\hline Number of channel(s) & 2 & 4 & 8 & 16 & 32 & 64 & 128 \\
\hline $\begin{array}{l}\text { CMFIR architecture-based up } \\
\text { converter with genetic algorithm } \\
\text { efficiency with respect to MAC } \\
\text { filter architecture-based up } \\
\text { converter }(\%)\end{array}$ & 86.96 & 87.02 & 87.12 & 90.89 & 90.91 & 90.53 & 90.55 \\
\hline $\begin{array}{l}\text { CMFIR architecture-based up } \\
\text { converter with genetic algorithm } \\
\text { efficiency with respect to CIC } \\
\text { filter architecture-based up } \\
\text { converter }(\%)\end{array}$ & 77.75 & 79.20 & 79.33 & 87.17 & 86.98 & 86.84 & 86.83 \\
\hline $\begin{array}{l}\text { CMFIR architecture-based up } \\
\text { converter with genetic } \\
\text { algorithm efficiency with } \\
\text { respect to CMFIR } \\
\text { architecture-based up converter } \\
\text { without genetic algorithm }(\%)\end{array}$ & 4.81 & 4.00 & 4.08 & 4.12 & 2.34 & 3.13 & 3.70 \\
\hline
\end{tabular}

\section{LUT - FLIP FLOP PAIRS UTILIZATION EFFICIENCY GRAPH}

$\leadsto$ with respect to MAC Filter Architecture Based Up Converter (\%)

$\longrightarrow$ with respect to CIC Filter Architecture Based Up Converter (\%)

$\multimap$ with respect to CMFIR Architecture Based Up Converter Without Genetic Algorithm (\%)

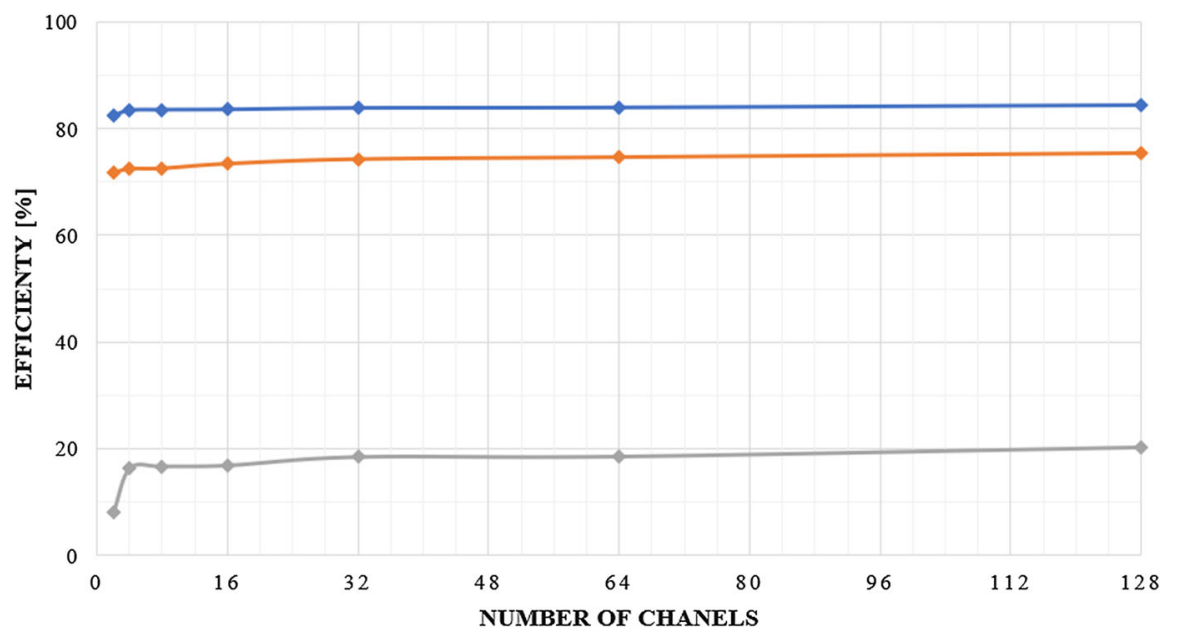

Fig. 8 LUT-flip flop pairs utilization efficiency graph with respect to other structures 
Table 7 Efficiency table of LUT-flip flop pairs utilization of CMFIR architecture-based up converter with genetic algorithm with respect to other up converters

\begin{tabular}{llllllll}
\hline Number of channel(s) & 2 & 4 & 8 & 16 & 32 & 64 & 128 \\
\hline $\begin{array}{l}\text { CMFIR architecture-based up } \\
\text { converter with genetic algorithm } \\
\text { efficiency with respect to MAC }\end{array}$ & 82.46 & 83.43 & 83.54 & 83.59 & 83.86 & 83.95 & 84.38 \\
$\begin{array}{l}\text { filter architecture-based up } \\
\text { converter (\%) }\end{array}$ & & & & & & & \\
$\begin{array}{l}\text { CMFIR architecture-based up } \\
\text { converter with genetic algorithm } \\
\text { efficiency with respect to CIC } \\
\text { filter architecture-based up }\end{array}$ & 71.70 & 72.44 & 72.53 & 73.43 & 74.32 & 74.72 & 84.38 \\
$\quad$ converter (\%) & & & & & & & \\
$\begin{array}{l}\text { CMFIR architecture-based up } \\
\text { converter with genetic } \\
\text { algorithm efficiency with }\end{array}$ & 8.16 & 16.33 & 16.67 & 16.84 & 18.42 & 18.50 & 20.19 \\
$\begin{array}{l}\text { respect to CMFIR } \\
\text { architecture-based up converter } \\
\text { without genetic algorithm }(\%)\end{array}$ & & & & & & & \\
\hline
\end{tabular}

- The multichannel system efficiency in terms of the average total power reduction is $89.40 \%$, the average dynamic power reduction is 53.96 , and the average static power reduction is $95.26 \%$ with respect to the MAC-based architectures;

- The multichannel system efficiency in terms of the average total power reduction is $42.43 \%$, the average dynamic power reduction is $40.47 \%$, and the average static power reduction is $47.93 \%$ with respect to the CIC-based architectures;

- The multichannel system efficiency in terms of the average total power reduction is $15.75 \%$, the average dynamic power reduction is $22.05 \%$, and the average static power reduction is $8.01 \%$ with respect to the CMFIR without genetic algorithmbased architectures.

The additional comparison of the obtained results in point of other researches $[3,5]$ was conducted. The comparison was realized with regard to total power. The results are presented in Table 8. The total power consumption was at least half less than in other studies. Additionally, the deep comparison was realized to [5] with regard to device utilization like LUT, flip flop, and slice LUT-flip flop pairs. The results are

Table 8 Comparison in point of total power between literature results and the proposed solution

\begin{tabular}{lc}
\hline FIR structure & Total \\
& power(watt) \\
\hline $\begin{array}{l}\text { FIR Filter developed using booth low power serial multiplier and serial adder, } \\
\text { combinational booth multiplier, shift/add multipliers, folding transformation [3] }\end{array}$ & 0.110 \\
$\begin{array}{l}\text { FIR developed using combination booth multiplier and carry look ahead adder [5] } \\
\text { Investigated in this article CMFIR filter after applying genetic algorithm }\end{array}$ & 0.242 \\
\hline
\end{tabular}


Table 9 Comparison in point of device utilization between literature results and the proposed solution

\begin{tabular}{llll}
\hline Device utilization & LUTs & Flip-flops & Slice LUT-flip flop pairs \\
\hline $\begin{array}{l}\text { FIR developed using combination booth } \\
\text { multiplier and carry look ahead adder [5] }\end{array}$ & 3056 & 2218 & 2604 \\
$\begin{array}{c}\text { Investigated in this article CMFIR filter } \\
\text { after applying genetic algorithm }\end{array}$ & 392 & 1850 & 384 \\
$\begin{array}{l}\text { Reduction of resource utilization in terms } \\
\text { of percentage (\%) }\end{array}$ & 87 & 17 & 85 \\
\hline
\end{tabular}

presented in Table 9. The obtained results are satisfying, and there is a decrease of at least $17 \%$ for each parameter.

\section{Conclusions}

This article proposes the Cascaded Multiple Accumulate Finite Impulse Response (CMFIR) filter-based sample rate converters. The CMFIR filter is the combination of CIC FIR and MAC FIR filters incorporating promising features of both filters. Investigation indicated that the proposed CMFIR solution ensures higher static power consumption efficiency, dynamic power consumption efficiency, total power consumption efficiency, register utilization efficiency, LUT utilization efficiency, LUT-flip flop pairs utilization efficiency than MAC and CIC structure. Additionally, the proposed application of the genetic algorithm to the CMFIR filter provides even better results. The proposed CMFIR filter may respond to the challenge of removing noise from images at low power consumption. Thus, in future, the CMFIR filter can be included as a part of the anti-fog driver assistance system. This application is a direction for future research of the authors.

Author Contributions Conceptualization, V.J., P.C., M.J.; methodology, V.J., and P.C.; software, V.J. and P.C.; validation, M.J.,V.B.; formal analysis, M.J.; investigation, V.J. and P.C.; resources, V.J. and P.C.; data curation, V.J. and P.C.; writing — original draft preparation, V.J. and P.C.; writing—review and editing, M.J. and V.B.; visualization, V.J. and M.J.; supervision, P.C., M.M. Z.L.; M.J. and A.V.; project administration, M.J.; funding acquisition, Z.L. All authors have read and agreed to the published version of the manuscript.

Funding This research was funded by Department of Computer Science Engineering, Techno India NJR Institute of Technology and Chair of Electrical Engineering Fundamentals, Wroclaw University of Science and Technology.

Data availability All data generated or analyzed during this study are included in this published article and its supplementary information files.

\section{Declarations}

Conflict of interest The authors declare no conflict of interest. 
Open Access This article is licensed under a Creative Commons Attribution 4.0 International License, which permits use, sharing, adaptation, distribution and reproduction in any medium or format, as long as you give appropriate credit to the original author(s) and the source, provide a link to the Creative Commons licence, and indicate if changes were made. The images or other third party material in this article are included in the article's Creative Commons licence, unless indicated otherwise in a credit line to the material. If material is not included in the article's Creative Commons licence and your intended use is not permitted by statutory regulation or exceeds the permitted use, you will need to obtain permission directly from the copyright holder. To view a copy of this licence, visit http://creativecommons.org/licenses/ by $/ 4.0 \%$.

\section{References}

1. M.R. Anawar et al., Fog computing: an overview of big IoT data analytics. Wirel. Commun. Mob. Comput. 2018, 1-22 (2018). https://doi.org/10.1155/2018/7157192

2. A. Asokan et al., Image processing techniques for analysis of satellite images for historical maps classification: an overview. Appl. Sci. 10(12), 4207 (2020). https://doi.org/10.3390/app10124207

3. Bhalke, S. et al.: FPGA implementation of efficient FIR Filter with quantized fixedpoint coefficients. In: 2013 International Conference on Emerging Trends in Communication, Control, Signal Processing and Computing Applications (C2SPCA) (IEEE, 2013), p. 1-6. https://doi.org/10.1109/C2SPCA.2013. 6749406

4. F. Damayanti et al., Detection and identification Indonesia license plate using background subtraction based on area. J. Phys. Conf. Ser. 1569, 022064 (2020). https://doi.org/10.1088/1742-6596/1569/2/ 022064

5. Deepika, Goel, N.: Design of FIR Filter using reconfigurable MAC unit. In: 2016 3rd International Conference on Signal Processing and Integrated Networks (SPIN) (IEEE, 2016), p. 312-315. https:// doi.org/10.1109/SPIN.2016.7566710.

6. T. Dewi et al., Fruit sorting robot based on color and size for an agricultural product packaging system. Bull Electr Eng Inform 9(4), 1438-1445 (2020). https://doi.org/10.11591/eei.v9i4.2353

7. E. Doganay et al.: Breast cancer classification from digital breast tomosynthesis using 3D multi-subvolume approach. In Medical Imaging 2020: Imaging Informatics for Healthcare, Research, and Applications ed. by T. M. Deserno, P.-H. Chen (SPIE, 2020), p. 12. https://doi.org/10.1117/12. 2551376.

8. E.R. Dougherty, Digital image processing methods (CRC Press, 2020)

9. S. Gavrilov et al.: Fast power loss calculation for digital static CMOS circuits. In: Proceedings European Design and Test Conference. ED \& TC 97 (IEEE Computer Society Press), pp. 411-415. https://doi. org/10.1109/EDTC.1997.582392.

10. A. Horé, O. Yadid-Pecht, On the design of optimal 2D filters for efficient hardware implementations of image processing algorithms by using power-of-two terms. J. Real-Time Image Process. 16(2), 429-457 (2019). https://doi.org/10.1007/s11554-015-0550-2

11. Y. Isobe, T. Kihara: First-order recursive CIC filters in time-interleaved VCO-based ADCs for directRF sampling receivers. In: 2019 IEEE Asia Pacific Conference on Circuits and Systems (APCCAS) (IEEE, 2019), p. 25-28. https://doi.org/10.1109/APCCAS47518.2019.8953087.

12. V. Jain et al.: Development of low power multi channel interpolator for system on chip in $4 \mathrm{G}$ application. In: 2014 IEEE Microwaves, Radar and Remote Sensing Symposium (MRRS). (IEEE, 2014), p. 111-114. https://doi.org/10.1109/MRRS.2014.6956677.

13. R. Kar et al.: Optimization of linear phase FIR band pass filter using particle swarm optimization with constriction factor and inertia weight approach. In: 2011 IEEE Symposium on Industrial Electronics and Applications (IEEE, 2011), p. 326-331. https://doi.org/10.1109/ISIEA.2011.6108725.

14. V. N. Kumar et al.: Design of area and power efficient digital FIR filter using modified MAC unit. In: 2015 2nd International Conference on Electronics and Communication Systems (ICECS) (IEEE, 2015), p. 884-887. https://doi.org/10.1109/ECS.2015.7125041.

15. P.R.G. Kurka, A.A. Díaz Salazar, Applications of image processing in robotics and instrumentation. Mech. Syst. Signal Process. 124, 142-169 (2019). https://doi.org/10.1016/j.ymssp.2019.01.015 
16. K. Lakhwani et al.: An enhanced approach to improve UIQI and PSNR of noised colored images using DWTT filter. In: 2018 International Conference on Computing, Power and Communication Technologies (GUCON) (IEEE, 2018), p. 289-293. https://doi.org/10.1109/GUCON.2018.8674928.

17. Y.-K. Lee et al., Feature point extraction model for improving semiconductor package inspection efficiency. Test Eng. Manag. 83, 4461-4469 (2020)

18. M. Liu, M. Wang: An efficient architecture for the modified DLMS algorithm using CIC filters. In: 2018 Eighth International Conference on Instrumentation \& Measurement, Computer, Communication and Control (IMCCC) (IEEE, 2018), p. 304-310. https://doi.org/10.1109/IMCCC.2018.00071.

19. G. Molnar et al., Design and Multiplierless Realization of Maximally Flat Sharpened-CIC Compensators. IEEE Trans. Circ. Syst. II Express Briefs. 65(1), 51-55 (2018). https://doi.org/10.1109/TCSII. 2017.2700081

20. W. A. Mustafa et al.: Effect of different filtering techniques on medical and document image. In: Lecture Notes in Electrical Engineering. pp. 727-736 (2021). https://doi.org/10.1007/978-981-15-5281-6_52.

21. N. Nahrawi et al.: Contrast enhancement approaches on medical microscopic images: a review. In: Lecture Notes in Electrical Engineering (2021), p. 715-726. https://doi.org/10.1007/978-981-15-52816 61.

22. S. S. Priya, M. Maheswari: Low-power area efficient reconfigurable multiplier architecture for FIR filter. In: 2017 2nd International Conference on Communication and Electronics Systems (ICCES) (IEEE, 2017), p. 654-658. https://doi.org/10.1109/CESYS.2017.8321160.

23. J.G. Proakis, D.G. Manolakis, Digital signal processing (PHI Publ, New Delhi, 2004)

24. R. Qureshi et al., Hyperspectral document image processing: Applications, challenges and future prospects. Pattern Recognit. 90, 12-22 (2019). https://doi.org/10.1016/j.patcog.2019.01.026

25. S. Rakesh, K. S. V. Grace: A survey on the design and performance of various MAC unit architectures. In: 2017 IEEE International Conference on Circuits and Systems (ICCS) (IEEE, 2017), p. 312-315. https://doi.org/10.1109/ICCS1.2017.8326011.

26. S. Ramamoorthy et al.: Enhancing intricate details of ultrasound PCOD scan images using tailored anisotropic diffusion filter (TADF). In: Intelligence in Big Data Technologies---Beyond the Hype ed by J. D. Peter et al. (Springer, Singapore, 2021), p. 43-52. https://doi.org/10.1007/978-981-15-5285-4_4.

27. S. S. Sahu et al.: Improved protein structural class prediction using genetic algorithm and artificial immune system. In: 2009 World Congress on Nature \& Biologically Inspired Computing (NaBIC) (IEEE, 2009), p. 731-735. https://doi.org/10.1109/NABIC.2009.5393488.

28. O. S. Salman, R. Klein. Anatomical region identification in medical X-ray computed tomography (CT) scans: development and comparison of alternative data analysis and vision-based methods. Neural Comput. Appl. (2020)

29. A. Samir et al.: A new architecture based on convolutional neural networks (CNN) for assisting the driver in fog environment. In: Proceedings of the 3rd International Conference on Smart City Applications - SCA '18 (ACM Press, New York, 2018), p. 1-5. https://doi.org/10.1145/3286606.3286862

30. F.E. da Silva Barbosa et al., A platform for cloudification of network and applications in the Internet of Vehicles. Trans. Emerg. Telecommun. Technol. 31, 5 (2020). https://doi.org/10.1002/ett.3961

31. B. R. Srinivasa Rao, B. Bala Tripura Sundari: An efficient reconfigurable FIR filter for dynamic filter order variation. In: 2019 International Conference on Communication and Electronics Systems (ICCES) (IEEE, 2019), p. 1724-1728. https://doi.org/10.1109/ICCES45898.2019.9002375.

32. S. Terai, T. Goto. Noise removal super-resolution for camera images utilizing total variation regularization method. In: 2020 IEEE 2nd Global Conference on Life Sciences and Technologies (LifeTech) (IEEE, 2020), p. 183-184. https://doi.org/10.1109/LifeTech48969.2020.1570619113.

33. T. Theocharides et al., Guest editorial: robust resource-constrained systems for machine learning. IEEE Des. Test. 37(2), 5-7 (2020). https://doi.org/10.1109/MDAT.2020.2971201

34. C.H. Trisos et al., Potentially dangerous consequences for biodiversity of solar geoengineering implementation and termination. Nat. Ecol. Evol. 2(3), 475-482 (2018). https://doi.org/10.1038/s41559017-0431-0

35. J. Vivek, A. Navneet. Design of multichannel sample rate convertor. J. Electr. Electron. Syst. 05(01) (2016). https://doi.org/10.4172/2332-0796.1000168.

36. S. Venkatraman et al.: Real time mold quality inspection in foundries using image processing techniques. In: 2020 International Conference on Emerging Trends in Information Technology and Engineering (ic-ETITE) (IEEE, 2020), p. 1-5. https://doi.org/10.1109/ic-ETITE47903.2020.215. 
37. T. Yu et al.: Noise power spectrum estimation of column fixed pattern noise in CMOS image sensors based on AR Model. In: 2019 Prognostics and System Health Management Conference (PHMQingdao). (IEEE, 2019), p. 1-5. https://doi.org/10.1109/PHM-Qingdao46334.2019.8943035.

38. S. Zhenhe et al.: FIR digital filter design and MATLAB simulation. In: Proceedings of 2012 International Conference on Measurement, Information and Control (IEEE, 2012), p. 677-680. https://doi. org/10.1109/MIC.2012.6273383.

Publisher's Note Springer Nature remains neutral with regard to jurisdictional claims in published maps and institutional affiliations.

\section{Authors and Affiliations}

\section{Vivek Jain ${ }^{1}$. Prasun Chakrabarti ${ }^{1}$ - Massimo Mitolo ${ }^{2}$. Zbigniew Leonowicz $^{3}$ - Michal Jasinski ${ }^{3}$ - Alexander Vinogradov ${ }^{4}$. Vadim Bolshev ${ }^{4}$}

$\bowtie$ Michal Jasinski

michal.jasinski@pwr.edu.pl

Vivek Jain

vivek.jain@technonjr.org

Prasun Chakrabarti

drprasun.cse@gmail.com

Massimo Mitolo

mmitolo@ivc.edu

Zbigniew Leonowicz

zbigniew.leonowicz@pwr.edu.pl

Alexander Vinogradov

schkolamolen@gmail.com

Vadim Bolshev

vadimbolshev@gmail.com

1 Department of Computer Science Engineering, Techno India NJR Institute of Technology, Udaipur, India

2 School of Integrated Design, Engineering and Automation, Irvine Valley College, Irvine, CA 92602, USA

3 Department of Electrical Engineering Fundamentals, Faculty of Electrical Engineering, Wroclaw University of Science and Technology, 50-370 Wroclaw, Poland

4 Laboratory of Power Supply and Heat Supply, Federal Scientific Agroengineering Center VIM, Moscow, Russia 109428 